\title{
EFEITO DA GERMINAÇÃO DE SOJA CV. BR-13 E PARANÁ SOBRE ÁCIDO FÍTICO, FÓSFORO TOTAL E INIBIDORES DE TRIPSINA ${ }^{1}$
}

\author{
MARA LUCIA LUIZ RIBEIRO², ELZA IOUKO IDA ${ }^{3}$ e MARIA CRISTINA NEVES DE OLIVEIRA ${ }^{4}$
}

\begin{abstract}
RESUMO - Este trabalho foi conduzido para avaliar o efeito da germinação sobre os constituintes antinutricionais da soja, ácido fítico, $\mathrm{P}$ total e inibidores de tripsina, que interferem na utilização de proteínas e outras substâncias. A diminuição no aproveitamento de nutrientes resulta em inibição de crescimento, hipoglicemia ou danos a tecidos animais. Para os ensaios foram utilizadas as cultivares de soja (Glycine max (L.) Merrill ) BR-13 e Paraná. As sementes foram incubadas em câmara de germinação a $25^{\circ} \mathrm{C}$ e $100 \%$ de umidade, de 0 a 72 horas, com coleta de amostras em intervalos eqüidistantes de seis horas. A cultivar Paraná apresentou teores superiores de ácido fítico, $\mathrm{P}$ total e inibidores de tripsina, em relação à cultivar BR-13. As análises de variância e comparações entre médias indicaram que houve aumentos significativos $(\mathrm{p}<0,05)$ nos teores de $\mathrm{P}$ total $(8,5 \%$ e 3,6\% nas cultivares BR-13 e Paraná, respectivamente) e nos níveis de inibidores de tripsina $(22,05 \%$ e $17,10 \%$ nas cultivares BR-13 e Paraná, respectivamente), e reduções nos teores de ácido fítico (15,96\% e 9,46\% nas cultivares BR-13 e Paraná, respectivamente), em 72 horas de germinação.
\end{abstract}

Termos para indexação: Glycine max, constituintes antinutricionais.

\section{GERMINATION EFFECT OF SOYBEAN CV. BR-13 AND PARANÁ ON PHITIC ACID, TOTAL P AND TRYPSIN INHIBITORS LEVELS}

\begin{abstract}
The aim of this work was to evaluate the effect of germination on the antinutritional constituents of soybean, phytic acid, total $\mathrm{P}$ and trypsin inhibitors that interfere with the utilization of proteins and other substances. The decrease of the nutrient utilization results in growth inhibition, hypoglycemia or damage to animal tissues. Seeds of soybean (Glycine max (L.) Merrill) cultivars BR-13 and Paraná were incubated in germination chamber at $25^{\circ} \mathrm{C}$ and $100 \%$ of humidity, from 0 to 72 hours, and samples were collected in intervals of six hours. The Paraná cultivar presented higher amount of phytic acid, total phosphorus and trypsin inhibitors, than the BR-13 cultivar. The analysis of variance and comparison among the means indicated that, in 72 hours of germination, there was a significant increase $(\mathrm{p}<0.05)$ on the amount of total phosphorus $(8.5 \%$ and $3.6 \%$ for BR-13 and Paraná cultivars, respectively) and on the level of trypsin inhibitors $(22.05 \%$ and $17.10 \%$ for BR-13 and Paraná cultivars, respectively) while the amount of phytic acid decreased $15.96 \%$ and $9.46 \%$ for BR-13 and Paraná cultivars, respectively.
\end{abstract}

Index terms: Glycine max, antinutritional constituents.

\footnotetext{
${ }^{1}$ Aceito para publicação em 25 de maio de 1998.

Extraído da Dissertação de Mestrado apresentada à Universidade Estadual de Londrina (UEL).

${ }^{2}$ Farmacêutica, Prof ${ }^{a}$ Assistente, Dep. de Bioquímica, Centro de Ciências Exatas, UEL, Caixa Postal 6001, CEP 86051-970 Londrina, PR

${ }^{3}$ Química, Prof ${ }^{\mathrm{a}}$ Adjunta, Dep. de Tecnologia de Alimentos e Medicamentos, Centro de Ciências Agrárias, UEL.

${ }^{4}$ Lic. em Matemática, M.Sc., Embrapa-Centro Nacional de Pesquisa de Soja (CNPSo), Caixa Postal 231, CEP 86001-970 Londrina, PR.
}

\section{INTRODUÇÃO}

A soja apresenta elevado valor nutritivo, determinado por sua composição protéica. Entretanto, a semente apresenta, em sua estrutura, constituintes que interferem na utilização destas proteínas e de outras substâncias. Estes constituintes são denominados de antinutricionais e podem interferir na disponibilidade de nutrientes, resultando em inibição de crescimento, hipoglicemia ou danos a tecidos, 
como pâncreas ou fígado (Liener, 1981). Entre estes constituintes, pode-se destacar o ácido fítico e os inibidores de tripsina.

$\mathrm{O}$ ácido fítico ou inositol 1,2,3,4,5,6 hexafosfato $\left(\mathrm{C}_{6} \mathrm{H}_{18} \mathrm{O}_{24} \mathrm{P}_{6}\right)$ encontra-se amplamente distribuído nos vegetais. Em cereais e leguminosas o teor de ácido fítico pode variar de 1 a 3\%, e constitui a principal forma de armazenamento de $\mathrm{P}$, correspondendo de 60 a $90 \%$ do P total (Graf, 1983). A soja e seus derivados contêm de 1 a $1,5 \%$ de ácido fítico que podem ser quelados com metais di e trivalentes, tais como Ca, Cu, Zn, Fe, Mg, Mn e Mo (Rackis, 1974; Finney, 1978; Bau \& Debry, 1979), e interagir com proteínas e vitaminas (Chang, 1977).

Na soja também são conhecidos os inibidores de tripsina, denominados de Kunitz e Bowman-Birk. Em face dos seus efeitos antinutricionais, vários estudos têm sido realizados para esclarecer o mecanismo de ação destes compostos, uma vez que ambos causam hipertrofia de pâncreas de ratos e aves (Wolf \& Cowan, 1975).

Para melhorar a qualidade nutricional da soja e utilizá-la como alimento, há necessidade de remover ou inativar esses constituintes indesejáveis. A criação de cultivares através de manipulação genética que contêm pequena ou nenhuma quantidade desses constituintes indesejáveis seria uma alternativa, porém requer estudos prolongados sobre a natureza química e bioquímica destes compostos, bem como as conseqüências agronômicas de rendimento da colheita, tolerância ao solo, necessidade de luz e água e resistência a pragas (Sathe \& Salunkhe, 1984). Outras formas de redução de componentes indesejáveis seriam os processos como moagem, hidratação, cozimento, fermentação, extração com solvente e germinação (Rackis et al., 1979; Bressani, 1983; Abdullah et al., 1984; Mostafa \& Rahma, 1987; Beléia et al., 1990).

O processo de germinação tem sido proposto como alternativa para melhorar as qualidades nutricionais da soja (Mostafa \& Rahma, 1987). Têm-se observado, neste processo, reduções nos teores de ácido fítico dependentes do tempo de germinação e da cultivar estudada (Abdullah et al., 1984; Suparmo \& Markakis, 1987). Durante o processo de germinação, as enzimas existentes na semente, entre elas as fitases, são rapidamente ativadas por simples hidratação (Irving \& Fontaine citados por Labouriau, 1983). Com a ativação das fitases, o ácido fítico é hidrolisado, liberando $\mathrm{H}_{3} \mathrm{PO}_{4}, \mathrm{Mg}^{2+}, \mathrm{Ca}^{2+}$ (Labouriau, 1983) e inositol. Conseqüentemente, durante a germinação ocorrem reduções nos teores de ácido fítico, o qual possivelmente aumentará a disponibilidade de minerais. Com relação aos inibidores de tripsina durante a germinação, os resultados encontrados são contraditórios, com relatos de aumento (Jimenez et al., 1985), redução (Bates et al., 1977; Bau \& Debry, 1979; Mostafa \& Rahma, 1987), ou pouca alteração (Collins \& Sanders, 1976) em sua atividade.

O presente trabalho foi desenvolvido com o objetivo de investigar os efeitos do processo de germinação sobre o teor de ácido fítico, $\mathrm{P}$ total e atividade de inibidores de tripsina em duas cultivares de soja, BR-13 e Paraná.

\section{MATERIAL E MÉTODOS}

As cultivares de soja (Glycine max (L.) Merrill) BR-13 e Paraná foram cedidas pela Empresa Brasileira de Pesquisa Agropecuária (Embrapa) - Centro Nacional de Pesquisa de Soja, Londrina, PR. As sementes foram pré-selecionadas para remoção das danificadas ou manchadas, e de materiais estranhos e semeadas em substrato de papel toalha umedecido em água destilada e dobrados em forma de rolo. Os rolos com cinqüenta grãos cada, foram colocados em câmara de germinação mantida a $25^{\circ} \mathrm{C}$ e $100 \%$ de umidade (Freed \& Ryan, 1978)

Foi utilizado o delineamento experimental inteiramente casualizado, com combinações de tratamentos em esquema fatorial ( 2 cultivares $x 13$ períodos de germinação), em quatro repetições.

Foram estabelecidos treze períodos de germinação para a amostragem com intervalos de seis horas entre eles, de 0 a 72 horas. O prolongamento da germinação acima deste período não é recomendável, em face do crescimento acentuado da radícula e aumento da probabilidade de crescimento de fungos (Abdullah et al., 1984). Ao término de cada período, as amostras foram imediatamente transferidas para um reservatório contendo $\mathrm{N}$ líquido $\left(-210^{\circ} \mathrm{C}\right)$. Posteriormente, as amostras foram liofilizadas, finamente moídas e armazenadas a $-20^{\circ} \mathrm{C}$, para análises. Sementes de soja não germinadas foram utilizadas como testemunha.

A determinação de umidade das amostras moídas (farinhas) foi realizada pelo método de estufa a $105^{\circ} \mathrm{C}$ (Instituto Adolfo Lutz, 1985). 
O ácido fítico foi extraído segundo o método descrito por Thompson \& Erdman (1982), obtendo-se o P fítico. O $\mathrm{P}$ fítico e o $\mathrm{P}$ total foram determinados colorimetricamente, após digestão das amostras, com ácido nítrico e ácido perclórico 4:1 (v/v), segundo Chen et al. (1956). Foi utilizado o fator 3,55 para converter o $\mathrm{P}$ fítico em ácido fítico. Este último e o $\mathrm{P}$ total foram expressos em miligramas de ácido fítico por grama de farinha de soja integral (mg/g FSI), e em porcentagem, em base seca, respectivamente

A atividade dos inibidores de tripsina foi determinada pelo método desenvolvido por Kakade et al. (1974), com modificação no processo de extração segundo Liu \& Markakis (1989). Uma unidade de tripsina (1 UT) foi arbitrariamente definida como um aumento de 0,01 unidades de absorbância a $410 \mathrm{~nm}$, por $10 \mathrm{~mL}$ de reação sob as condições definidas. Os níveis de inibidores de tripsina foram expressos como UIT/mg FSI, em base seca.

Foram realizados estudos exploratórios para identificação de dados discrepantes que comprometiam a homogeneidade de variância dos tratamentos em estudo. Posteriormente, foram realizadas análises de variância para os dados obtidos, e o teste de Duncan foi utilizado para comparações múltiplas de médias dos tratamentos, a 5\% de probabilidade.

\section{RESULTADOS E DISCUSSÃO}

A análise de variância dos resultados obtidos na determinação do teor de ácido fítico indicou diferenças significativas entre cultivares, períodos de germinação e interação cultivar x períodos de germinação. Na Tabela 1 observam-se as médias da variável teor de ácido fítico com relação à interação cultivar $\mathrm{x}$ períodos de germinação. Quando comparadas as duas cultivares, dentro de cada período de germinação, nota-se que os teores de ácido fítico, na cultivar Paraná foram superiores em relação à cultivar BR-13. As cultivares BR-13 e Paraná apresentaram reduções significativas nos teores de ácido fítico à medida que aumentou o período de germinação. Nas duas cultivares, o menor teor de ácido fítico foi obtido em 72 horas de germinação. Ao final de 72 horas de germinação, houve um decréscimo no teor desta variável de 15,96 e 9,46\% nas cultivares BR-13 e Paraná, respectivamente. Resultados similares foram encontrados por Ahn \& Yang (1985) e Abdullah et al. (1984), com reduções nos teores de ácido fítico entre 10,8 e
$31 \%$, no mesmo período de germinação, em diferentes cultivares de soja.

Os resultados de teor de $\mathrm{P}$ podem ser observados na Tabela 2. A análise de variância indicou que houve diferenças significativas nos teores percentuais de $\mathrm{P}$ total em relação à cultivares, períodos de germinação e interação cultivar x períodos de germinação. Houve pouca variabilidade nos dados de laboratório, o que contribuiu para um baixo valor de coeficiente de variação e refletiu em alta precisão nas diferenças entre os efeitos médios de $\mathrm{P}$ total. O teste de Duncan indica diferenças significativas entre os períodos de germinação, apesar de os dados obtidos serem próximos entre si.

A cultivar Paraná apresentou teores mais elevados de $\mathrm{P}$ total em relação à $\mathrm{BR}-13$, exceto no período de 48 horas. A literatura apresenta contradições nos resultados do teor de $\mathrm{P}$ total em soja germinada por 72 horas. Khader (1983) e Bau \& Debry (1979) encontraram um decréscimo de 14,9 e $16 \%$, respectivamente, no teor de P total. Porém, Ahn \& Yang (1985) observaram um aumento de $7,2 \%$ no teor desta variável, o que está de acordo com os resultados obtidos neste trabalho.

TABELA 1. Médias de teor de ácido fítico (mg/g de farinha de soja integral - FSI) com relação à interação cultivar $x$ períodos de germinação ${ }^{1}$.

\begin{tabular}{|c|c|c|}
\hline \multirow{2}{*}{$\begin{array}{c}\text { Períodos } \\
\text { de germinação } \\
\text { (hora) }\end{array}$} & \multicolumn{2}{|c|}{ Cultivar } \\
\hline & $\begin{array}{c}\text { BR-13 } \\
(\mathrm{mg} / \mathrm{g} \text { FSI })\end{array}$ & $\begin{array}{c}\text { Paraná } \\
(\mathrm{mg} / \mathrm{g} \text { FSI })\end{array}$ \\
\hline 0 & $13,03 \mathrm{abB}$ & $16,71 \mathrm{aA}$ \\
\hline 6 & $13,48 \mathrm{aB}^{2}$ & $16,57 \mathrm{abA}$ \\
\hline 12 & $12,27 b^{2}$ & $16,25 \mathrm{abcA}$ \\
\hline 18 & $12,49 \mathrm{bB}$ & $15,99 \mathrm{bcA}$ \\
\hline 24 & $11,30 \mathrm{cdB}^{2}$ & $16,44 \mathrm{abA}$ \\
\hline 30 & $12,89 \mathrm{abB}$ & $16,76 \mathrm{aA}^{2}$ \\
\hline 36 & $13,67 \mathrm{aB}^{2}$ & $16,71 \mathrm{aA}^{2}$ \\
\hline 42 & $11,05 \mathrm{~dB}$ & $15,80 \mathrm{cA}$ \\
\hline 48 & $12,19 \mathrm{bcB}$ & $16,36 \mathrm{abcA}$ \\
\hline 54 & $12,74 \mathrm{abB}^{2}$ & $16,00 \mathrm{bcA}$ \\
\hline 60 & $12,77 \mathrm{abB}^{2}$ & $15,81 \mathrm{cA}$ \\
\hline 66 & $12,06 \mathrm{bcB}$ & $15,23 \mathrm{dA}$ \\
\hline 72 & $10,95 \mathrm{~dB}^{2}$ & $15,13 \mathrm{dA}^{2}$ \\
\hline
\end{tabular}

1 Médias seguidas da mesma letra minúscula na coluna e maiúscula na linha não diferem significativamente entre si pelo teste de Duncan, a 5\% de probabilidade; C.V. $(\%)=3,19 ; \mathrm{F}$. (períodos $\mathrm{x}$ cultivares $)=2,32$; $\operatorname{Pr}(\mathrm{F})=0,0151$

2 Resultados obtidos através da média de três repetições 
Considerando o teor de P total (Tabela 2) e de ácido fítico (Tabela 1), pode-se fazer uma relação entre os teores de $\mathrm{P}$ total e $\mathrm{P}$ fítico durante a germinação das cultivares de soja. No tempo zero, tem-se que 62,41 e $68,26 \%$ do P total, nas cultivares BR-13 e Paraná, encontram-se sob a forma de ácido fítico. Ao término de 72 horas, estes valores diminuem para 48,28 e $65,30 \%$ de $P$ fítico, respectivamente. Levando-se em conta que, durante a germinação, os teores de $\mathrm{P}$ total aumentaram, e houve uma diminuição no teor de ácido fítico, observou-se um aumento na disponibilidade de $P$, reduzindo-se assim, os efeitos indesejáveis deste constituinte. Este comportamento foi mais acentuado na cultivar BR-13.

Os resultados dos níveis de inibidores de tripsina, apresentaram, na análise de variância, resposta altamente significativa em períodos de germinação e interação cultivar $x$ períodos de germinação. Os resultados diferiram estatisticamente entre si, pelo teste de Duncan, a 5\% de probabilidade (Tabela 3). Pela interação cultivar x períodos de germinação, observa-se que após 72 horas de germinação houve um acréscimo de $22,05 \%$, nos níveis de inibidores de

TABELA2. Médias de teor de fósforo total (g/100 g) com relação à interação cultivar $x$ períodos de germinação ${ }^{1}$.

\begin{tabular}{cll}
\hline $\begin{array}{c}\text { Períodos } \\
\text { de germinação } \\
\text { (hora) }\end{array}$ & \multicolumn{2}{c}{ Cultivar } \\
\hline 0 & $0,588 \mathrm{fB}-13$ & \multicolumn{1}{c}{$\begin{array}{c}\text { Paraná } \\
(\mathrm{g} / 100 \mathrm{~g})\end{array}$} \\
\hline 6 & $0,613 \mathrm{deB}$ & $0,690 \mathrm{bcA}$ \\
12 & $0,628 \mathrm{bcdB}$ & $0,695 \mathrm{abcA}$ \\
18 & $0,618 \mathrm{cdeB}{ }^{2}$ & $0,707 \mathrm{abA}$ \\
24 & $0,618 \mathrm{cdeB}$ & $0,683 \mathrm{cdA}$ \\
30 & $0,620 \mathrm{cdeB}$ & $0,715 \mathrm{aA}$ \\
36 & $0,610 \mathrm{eB}$ & $0,713 \mathrm{abA}$ \\
42 & $0,608 \mathrm{eB}{ }^{2}$ & $0,697 \mathrm{abcA}$ \\
48 & $0,635 \mathrm{abcA}{ }^{2}$ & $0,663 \mathrm{deA}$ \\
54 & $0,645 \mathrm{aB}$ & $0,708 \mathrm{abA}$ \\
60 & $0,635 \mathrm{abcB}$ & $0,703 \mathrm{abcA}$ \\
66 & $0,635 \mathrm{abcB}$ & $0,698 \mathrm{abcA}$ \\
72 & $0,638 \mathrm{abB}$ & $0,660 \mathrm{eA}$ \\
\hline
\end{tabular}

1 Médias seguidas da mesma letra minúscula na coluna e maiúscula na linha não diferem significativamente entre si pelo teste de Duncan, a 5\% de probabilidade; C.V. $(\%)=1,91 ; \mathrm{F}$ (períodos $\mathrm{x}$ cultivares $)=7,13$; $\operatorname{Pr}(\mathrm{F})=0,0001$

2 Resultados obtidos através da média de três repetições tripsina, na cultivar BR-13, e de $17,10 \%$, na cultivar Paraná. Na cultivar BR-13 os maiores valores encontram-se nos períodos de 12 e 18 horas de germinação, não diferindo estatisticamente entre si, e os menores valores ocorreram na testemunha e no período de seis horas. Na cultivar Paraná, os maiores valores de níveis de inibidores de tripsina ocorreram nos períodos de 42, 48, 54, 66 e 72 horas, e o menor valor ocorreu na testemunha. Comparando-se as duas cultivares, observa-se que nos períodos de 30 , 36 e 60 horas, os resultados das duas cultivares foram similares. Nos períodos de 12, 18 e 24 horas os valores dos níveis de inibidores de tripsina foram superiores na cultivar BR-13, e nos demais períodos a superioridade ocorreu na cultivar Paraná.

Foram observados resultados contraditórios em relação à variação nos níveis de inibidores de tripsina durante a germinação. Jimenez et al. (1985) observaram um aumento na atividade de inibidor de tripsina de 12,83\%, em 72 horas. Collins \& Sanders (1976), Bau \& Debry (1979), Khader (1983), Abdullah et al. (1984) e Mostafa \& Rahma (1987) obtiveram reduções na atividade dos inibidores, em diferentes culti-

TABELA3. Médias de níveis de inibidores de tripsina (UIT/mg de farinha de soja integral - FSI) com relação à interação cultivar $x$ períodos de germinação ${ }^{1}$.

\begin{tabular}{ccc}
\hline \multirow{2}{*}{$\begin{array}{c}\text { Períodos } \\
\text { de germinação } \\
\text { (hora) }\end{array}$} & \multicolumn{2}{c}{ Cultivar } \\
\cline { 2 - 3 }$(\mathrm{BIT} / \mathrm{g}$ FSI) & $\begin{array}{c}\text { Paraná } \\
\text { (UIT/g FSI) }\end{array}$ \\
\hline 0 & $37,09 \mathrm{gB}$ & $40,58 \mathrm{hA}^{2}$ \\
6 & $43,36 \mathrm{fB}$ & $44,66 \mathrm{dA}$ \\
12 & $48,05 \mathrm{aA}$ & $45,98 \mathrm{cB}$ \\
18 & $47,85 \mathrm{aA}$ & $42,25 \mathrm{fB}$ \\
24 & $45,89 \mathrm{cA}$ & $41,50 \mathrm{gB}$ \\
30 & $44,14 \mathrm{eA} A^{2}$ & $44,52 \mathrm{dA}$ \\
36 & $44,12 \mathrm{eA}$ & $43,76 \mathrm{eA}{ }^{2}$ \\
42 & $45,85 \mathrm{cB}$ & $47,82 \mathrm{aA}$ \\
48 & $45,10 \mathrm{~dB}$ & $47,91 \mathrm{aA}$ \\
54 & $45,36 \mathrm{~dB}$ & $47,86 \mathrm{aA}$ \\
60 & $46,82 \mathrm{bA}$ & $46,72 \mathrm{bA}$ \\
66 & $45,09 \mathrm{~dB}$ & $47,77 \mathrm{aA}$ \\
72 & $45,27 \mathrm{~dB}$ & $47,52 \mathrm{aA}$ \\
\hline
\end{tabular}

${ }^{1}$ Médias seguidas da mesma letra minúscula na coluna e maiúscula na linha não diferem significativamente entre si pelo teste de Duncan, a 5\% de probabilidade; C.V. $(\%)=0,70 ; \mathrm{F}$ (períodos $\mathrm{x}$ cultivares $)=154,75$; $\operatorname{Pr}(\mathrm{F})=0,0001$

2 Resultados obtidos através da média de três repetições 
vares, que variaram entre 6,3 e $45 \%$, no mesmo período de germinação.

\section{CONCLUSÕES}

1. No período de 72 horas de germinação, os teores de ácido fítico diminuem $15,96 \%$ e $9,46 \%$ nas cultivares BR-13 e Paraná, respectivamente.

2. Os teores de $\mathrm{P}$ total aumentam $8,5 \%$ na cultivar BR-13, em 72 horas de germinação e $3,6 \%$ na cultivar Paraná, em 30 horas de germinação.

3. Os níveis de inibidores de tripsina aumentam $22,05 \%$ e $17,10 \%$ nas cultivares BR-13 e Paraná, respectivamente, em 72 horas de germinação.

\section{REFERÊNCIAS}

ABDULLAH, A.; BALDWIN, R.E.; MINOR, H. Germination effects on flatus-causing factors and antinutrients of mungbeans and two strains of small-seeds soybeans. Journal of Food Protection, Ames, v.47, n.6, p.441-444, 1984.

AHN, B.; YANG, C.B. Effects of soaking, germination, incubation and autoclaving on phytic acid in seeds. Korean Journal of Food Science and Technology, v.17, n.6, p.516-521, 1985.

BATES, R.P.; KNAPP, F.W.; ARAUJO, P.E. Protein quality of green-mature, dry mature and sprouted soybeans. Journal of Food Science, Chicago, v.42, p.271-272, 1977.

BAU, H.M.; DEBRY, G. Germinated soybean protein products chemical and nutritional evaluation. Journal of the American Oil Chemists' Society, Champaign, v.56, n.3, p.160-162, 1979.

BELÉIA, A.; IDA, E.I.; LETHI, T.T. Distribuição de fósforo e ácido fítico durante o processamento de extrato hidrossolúvel de soja. Arquivos de Biologia e Tecnologia, Curitiba, v.33, n.4, p.623-629, 1990

BRESSANI, R. Effect of chemical changes during storage and processing on the nutritional quality on common beans. Food and Nutrition Bulletin, Tokyo, v.5, n.1, p.23-34, 1983.

CHANG, R. Phytate: removal from whole dry beans by enzimatic hydroysis and diffusion. Journal of Food Science, Chicago, v.42, n.4, p.1098-1101, 1977.
CHEN, P.S.; TORIBARA, T.Y.; WARNER, H. Microdetermination of phosphorus. Analytical Chemistry, Washington, v.28, n.11, p.1756-1758, 1956.

COLLINS, J.L.; SANDERS, G.G. Changes in trypsin inhibitory activity in some soybean varieties during maturation and germination. Journal of Food Science, Chicago, v.41, p.168-172, 1976.

FINNEY, P.L. Potential for the use of germinated wheat and soybeans to enhance human nutrition. Advances in Experimental Medicine and Biology, New York, v.105, p.681-701, 1978.

FREED, R.C.; RYAN, D.S. Changes in Kunitz trypsin inhibitor during germination of soybean: an immunoelectrophoresis assay system. Journal of Food Science, Chicago, v.43, p.1316-1319, 1978.

GRAF, E. Aplications of phitic acid. Journal of the American Oil Chemists' Society, Champaign, v.60, n.11, p.1861-1867, 1983.

INSTITUTO ADOLFO LUTZ. Normas Analíticas. São Paulo: Instituto Adolfo Lutz, 1985. 371p.

JIMENEZ, M.J.M.; ELIAS, L.G.; BRESSANI, R.; NAVARRETE, D.A.; GÓMEZ-BRENES, R.; MOLINA, M.R. Estudios bioquimicos y nutricionales de la semilla germinada de soya. Archivos Latinoamericanos de Nutricion, Guatemala, v.35, n.3, p.481-490, 1985.

KAKADE, M.L.; RACKIS, J.J.; Mc GHEE, J.E.; PUSKI, G. Determination of trypsin inhibitor activity of soy products: a collaborative analysis of an improved procedure. Cereal Chemistry, St. Paul, v.51, p.376$-382,1974$

KHADER, V. Nutritional studies on fermented, germinated and baked soya bean (Glycine max) preparations. Journal of Plant Foods, London, v.5, p.31-37, 1983.

LABOURIAU, L.G. A germinação das sementes Washington: Secretaria Geral da Organização dos Estados Americanos, 1983. 171p.

LIENER, I.E. Factors affecting the nutritional quality of soya products. Journal of the American Oil Chemists' Society, Champaign, v.58, n.3, p.406$-415,1981$.

LIU, K.; MARKAKIS, P. An improved colorimetric method determining antitryptic activity in soybean 
products. Cereal Chemistry, St. Paul, v.66, n.5, p.415-422, 1989.

MOstafA, M.M.; RAHMA, E.H. Chemical and nutritional changes in soybean during germination. Food Chemistry, Essex, v.23, p.257-275, 1987.

RACKIS, J.J. Biological and physiological factors in soybeans. Journal of the American Oil Chemists' Society, Champaign, v.51, n.1, p.161A-174A, 1974

RACKIS, J.J.; SESSA, D.J.; HONIG, D.H. Flavor problems of vegetable food proteins. Journal of the American Oil Chemists' Society, Champaign, v.56, n.3, p.262-271, 1979.
SATHE, S.K.; SALUNKHE, D.K. Technology of removal of unwanted components of dry beans. CRC Critical Revieus in Food Science and Nutritions, Boca Raton, v.21, n.1, p.263-287, 1984.

SUPARMO; MARKAKIS, P. Tempeh prepared from germinated soybeans: a research note. Journal of Food Science, Chicago, v.52, n.6, p.1736-1737, 1987.

THOMPSON, D.B.; ERDMAN, J.W. Phytic acid determination in soybeans. Journal of Food Science, Chicago, v.47, n.2, p.513-517, 1982.

WOLF, W.J.; COWAN, J.C. Soybean as a food source. Cleveland, CRC, 1975. 101p. 